\title{
НЕКОТОРЫЕ ЗАКОНОМЕРНОСТИ СОСТАВА СМОЛЫ ПОЛУКОКСОВАНИЯ ЭСТОНСКОГО ГОРЮЧЕГО СЛАНЦА-КУКЕРСИТА
}

В работе ['] было высказано предположение, что в керогене эстонского сланца-кукерсита в малоизмененной форме присутствуют остатки нормальных жирных кислот $\mathrm{C}_{14}-\mathrm{C}_{18}$. Указанные насыщенные и ненасыщенные кислоты являются составной частью исходного биологического материала формирования керогена - морского планктона. Предполагалось, что в структуре керогена присутствуют алкильные цепн, содержащие 13, 15 и 17 атомов углерода и связанные с ядром керогена посредством углерод-углеродной связи; они являются декарбоксилированными остатками жирных кислот. Также было показано, что основное количество алифатического углерода находится в цепях, содержащих 7-10 атомов углерода. Әти более короткие цепи являются, по всей вероятности, остатками полимеризовавшихся ненасыщенных жирных кислот. Получены свидетельства в пользу того, что часть ароматических структур керогена и фрагменты, содержащие кислородные соединения, являются продуктами фоссилизации жирных кислот.

Oпределенные возможности для получения данных о структуре керогена открывает низкотемпературная термическая деструкция - метод исследования состава смол полукоксования сланца. Было установлено, что продукты термолиза в целом правильно отражают строение керогена и вторичные реакции протекают в условиях полукоксования незначительно. Исследования показали, что среди нормальных углеводородов $\mathrm{C}_{12}-\mathrm{C}_{17}$ преобладают парафины с нечетным числом атомов углерода, а для 1-олефинов характерна повышенная концентрация гомологов, имеющих в молекуле четное число атомов углерода. Указанное явление обусловлено по всей видимости тем, что парафины образуются при разрыве $\alpha$-связи у ядра керогена (углеродная цепь отрывается целиком), a 1 -олефины - при $\beta$-расщеплении (образуется олефин, содержащий на один атом углерода меньше, чем исходная цепь).

Кроме состава продуктов термической деструкции органических соединений, значительное, иногда даже определяющее влияние на раскрытие структуры исходного вещества оказывают условия разложения. В настояшей работе объектами сравнительного исследования были нормальные углеводороды смол полукоксования сланца-кукерсита на различных установках: в промышленных генераторах, туннельных печах, опытном генераторе Института сланцев [ $\left.{ }^{2}\right]$, а также в лабораторных условиях [3]. Цель работы - обобщить данные о составе сланцевой смолы, 


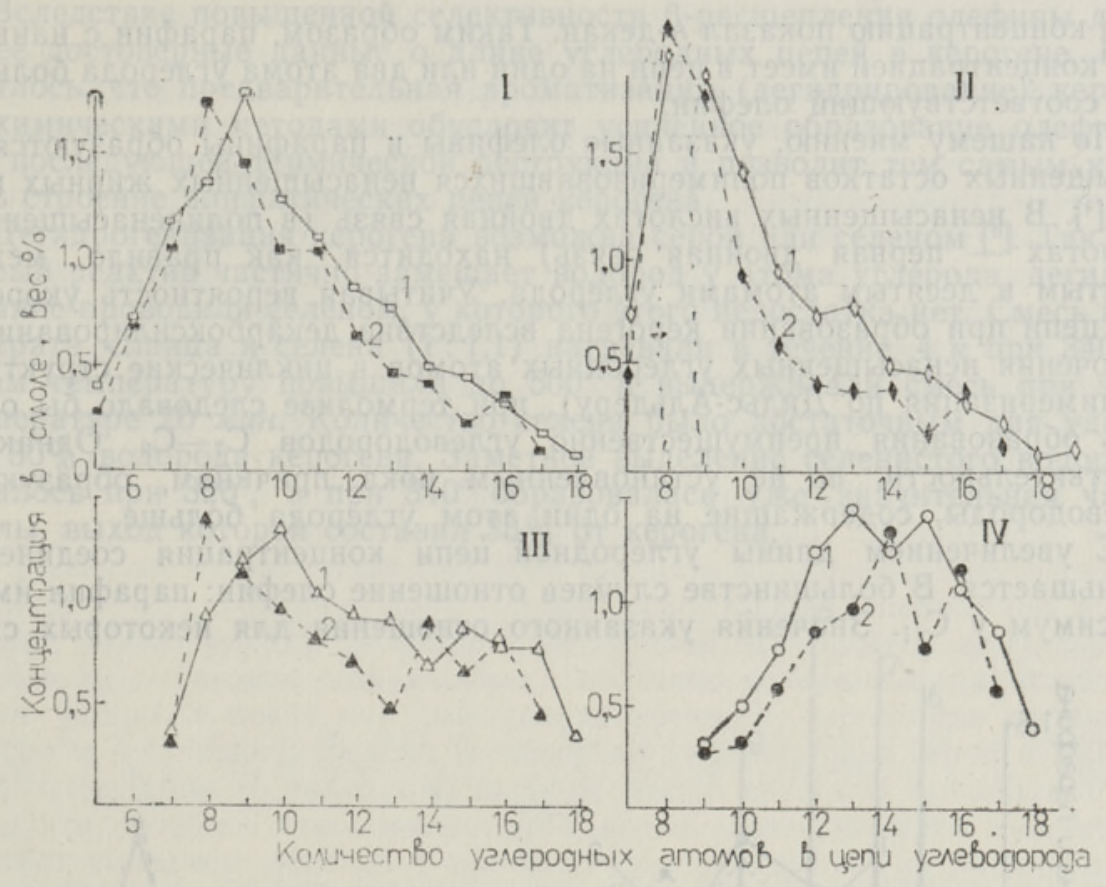

Рнс, 1. Концентрация нормальных парафинов (f) и 1-олефинов (2) в суммарной смоле полукоксования эстонского горючего сланца в зависнмости от длины углеродной цепи.

Установки полукоксования: I - туннельные печи; II - лабораторная установка, работаюшая по стандартному режиму; III - опытный генератор; IV - промышленные генераторы.

выявить имеющиеся закономерности и установить несоответствия между характером продуктов термолиза и предполагаемой структурой исходного керогена.

Парафины и олефины выделяли из суммарной смолы методом препаративной тонкослойной хроматографии, позволяющим избежать нежелательных реакций изомеризацин олефинов [4]. Состав выделенных групп определяли газохроматографически. Приведенные данные являются средними анализа $3-5$ проб.

На рис. 1 представлены данные о концентрации в смоле нормальных парафинов и 1-олефинов в зависимости от длины углеродной цепи. Содержание других изомеров н-олефинов, количество которых по сравнению с 1-олефинами значительно меньше, в данной работе не обсуждается. Отметим лишь, что относительная концентрация 2-олефинов весьма постоянна и независимо от длины углеродной цепи составляет в среднем $20 \%$ от суммы всех изомеров. Значительное количество олефи. нов с длиной цепи в $12-17$ атомов углерода имеет двойную связь в середине цепи.

На первый взгляд в составах углеводородов всех установок наблюдается явное различие. В смоле промышленных генераторов, вследствие особенностей генераторного процесса, отсутствуют низкокипящие соединения, частично они теряются также в смоле опытного генератора. В смоле других установок наивысшую концентрацию имеют углеводороды $\mathrm{C}_{7}-\mathrm{C}_{10}$. Из олефинов максимальную концентрацию обычно имеет октен-1. Сложнее обстоит дело с парафинами: в большинстве случаев преобладает $\boldsymbol{H}$-нонан, но во всех пробах опытного генератора наивыс- 
шую концентрацию показал н-декан. Таким образом, парафин с наивысшей концентрацией имеет в цепи на один или два атома углерода больше, чем соответствующий олефин.

По нашему мнению, указанные олефины и парафины образуются из насыщенных остатков полимеризовавшихся ненасыщенных жирных кислот [1]. В ненасыщенных кислотах двойная связь (в полиненасыщенных кислотах - первая двойная связь) находится, как правило, между девятым и десятым атомами углерода. Учитывая вероятность укорочения цепи при образовании керогена вследствие декарбоксилирования и включения ненасыщенных углеродных атомов в циклические структуры (полимеризация по Дильс-Альдеру), при термолизе следовало бы ожидать образования преимущественно углеводородов $\mathrm{C}_{7}-\mathrm{C}_{9}$. Однако в действительности, по не установленным пока причинам, образуются углеводороды, содержащие на один атом углерода больше.

С увеличением длины углеродной цепи концентрация соединений уменьшается. В большинстве случаев отношение олефин: парафин имеет максимум у $\mathrm{C}_{11}$. Значения указанного отношения для некоторых смол

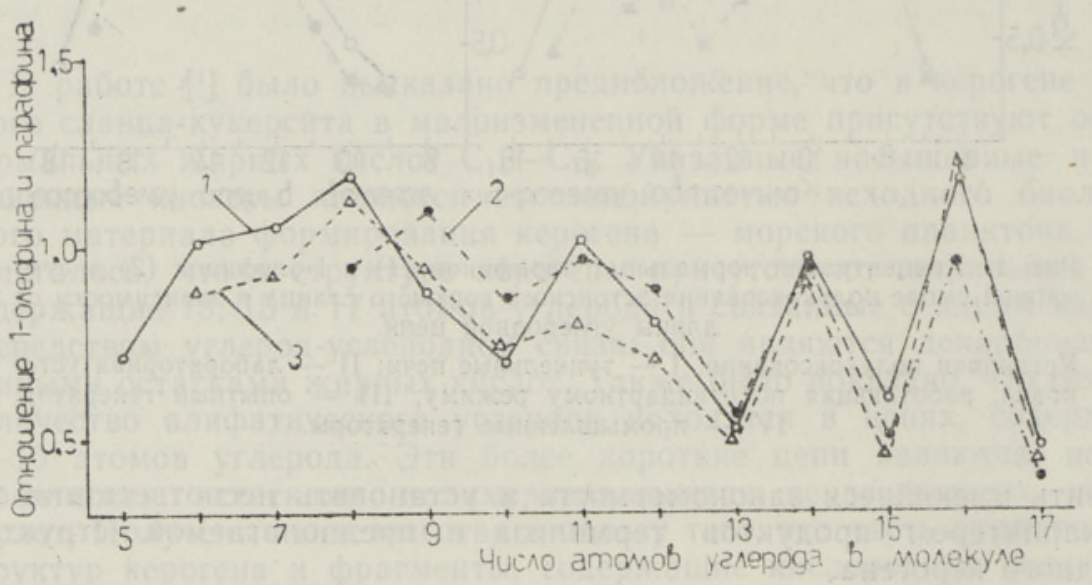

Pис. 2. Отношение концентраций 1-олефина и соответствующего $\boldsymbol{\mu}$-парафина в зависимости от длины углеродной цепи для следующих смол полукоксования:

1 - смола туннельных печей; 2 - смола промышленных генераторов; 3 - смола опытного генератора.

графически представлены на рис. 2. При дальнейшем увеличении длины углеродной цепи наблюдается характерное ступенчатое изменение количественного состава компонентов, что особенно резко проявляется при сравнении концентраций парафина и соответствующего 1-олефина (см. рис. 2).

При сравнении состава углеводородов отдельных установок полукоксования выявляется, что они различаются только в низкокипящей области, а углеводороды $\mathrm{C}_{12}-\mathrm{C}_{17}$ имеют во всех случаях близкий количественный состав. Кроме того, концентрация парафинов не изменяется так скачкообразно, как концентрация олефинов. Следовательно, $\alpha$-расщепление у гидроароматического ядра (образование парафина) происходит не так селективно, как $\beta$-разрыв у ароматического ядра (образование олефина). Әтот вывод согласуется с данными [5]. Возможно, что часть парафинов образуется в результате перераспределения водорода по-иному механизму. 
Вследствие повышенной селективности $\beta$-расщепления олефины даюг более достоверные данные о длине углеродных цепей в керогене. Нам казалось, что предварительная ароматизация (дегидрирование) керогена химическими методами обусловит усиленное образование олефинов при последующей термической деструкции и позволит тем самым уточнить строение алифатических цепей керогена.

Дегидрогенизация керогена возможна серой или селеном []. Так как первый реактив частично замещает водород у атома углерода, дегидрирование проводили селеном, у которого этого недостатка нет. Смесь концентрата сланца и селена $(1: 1,1)$ нагревали в течение 4 ч при $340^{\circ} \mathrm{C}$, затем температуру повышали до $500^{\circ}$ и выдерживали смесь при этой температуре 20 мин. Количество селена было достаточным для удаления $30 \%$ водорода керогена. Заметное выделение селенистого водорода началось при $320^{\circ}$, а при $340^{\circ}$ образовалась уже значительная часть смолы, выход которой составил $35 \%$ от керогена.

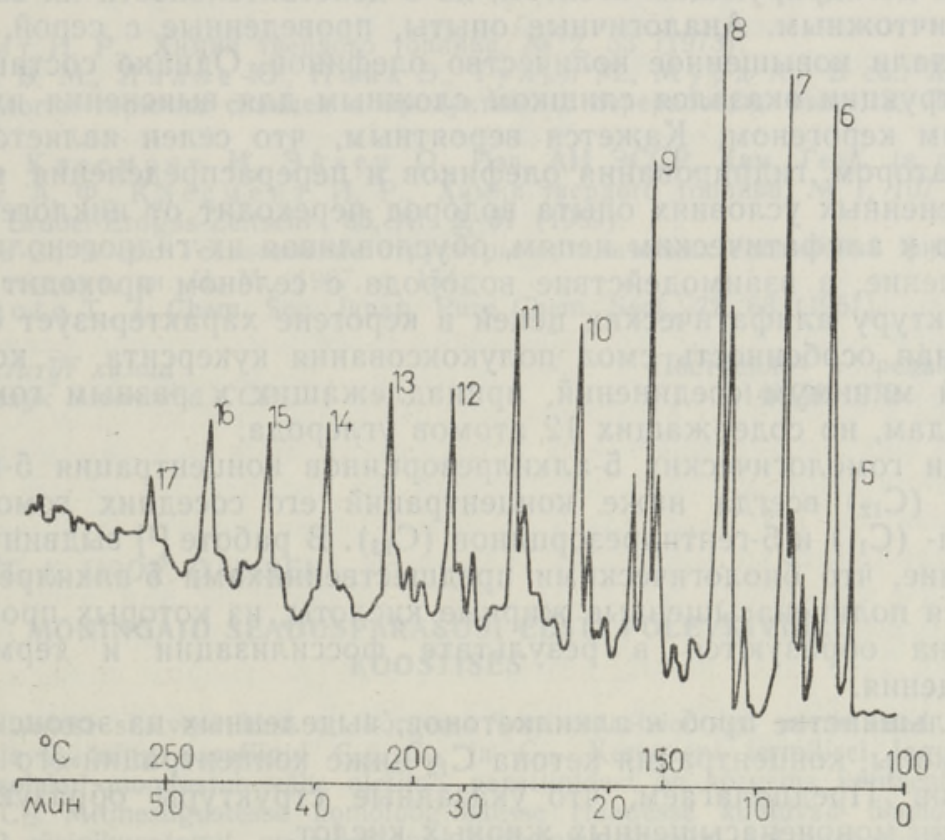

Рис. 3. Хроматограмма смолы полукоксования керогена, дегидрированного селеном. Номер пика соответствует количеству углеродных атомов в нормальном парафине. Условия хроматографирования: аппарат УХ-1, длина колонки $6 \mu, \varnothing 4 / 6 м \mu, 5 \%$ апиезона $L$ на хромосорбе $G(45-60$ меш), расход водорода $40-60 \mathrm{M} /$ мин.

Хроматограмма смолы, полученной при термолизе керогена, предварительно дегидрированного селеном, представлена на рис. 3. Сразу бросается в глаза чрезвычайно низкая концентрация олефинов (в примененных условиях газовой хроматографии 1-олефин выходит из колонки раньше соответствующего парафина). Как и в обычных смолах полукоксования, из олефинов самую высокую концентрацию имеет октен-1. Количество олефинов $\mathrm{C}_{12}-\mathrm{C}_{17}$ незначительное, вследствие чего они не могут характеризовать исходный кероген.

Интересен состав парафинов, из которых повышенную концентрацию имеет $\mathrm{C}_{11}$, немного больше и $\mathrm{C}_{16}$. Пик $\mathrm{C}_{13}$ тоже высокий, но это наблюдается и в обычных смолах полукоксования. 
T. Мацумото [7] дегидрировал в присутствии селена гексадецилциклогексан при $350-370^{\circ}$ и получил с $60 \%$-ным выходом соответствующее фенильное производное наряду с $5 \%$ пентадекана и небольшого количества толуола. Это показывает, что имеет место $\beta$-расщепление, но образуется парафин. На основании этих данных в керогене эстонского горючего сланца должны в большом количестве присутствовать углеродные цепи, содержащие 12 и 14 атомов углерода. Однако согласно приведенным выше данным о составе парафинов и олефинов смол обычного полукоксования, повышенную концентрацию в керогене имеют цепи с 13, 15 и 17 атомами углерода. Нам кажется, что большинство экспериментальных данных, накопленных к настоящему времени, говорит в пользу «нечетных» углеродных цепей в керогене. Вопрос требует, конечно, дальнейшего уточнения.

В результате обработки керогена селеном при термолизе мы ожидали образования большого количества олефннов, поскольку селен является дегидрирующим агентом, но в действительности их выход оказался ничтожным. Аналогичные опыты, проведенные с серой, действительно дали повышенное количество олефинов. Однако состав продуктов деструкции оказался слишком сложным для выяснения их связи с исходным керогеном. Кажется вероятным, что селен является также катализатором гидрирования олефинов и перераспределения водорода. В примененных условиях опыта водород переходит от циклогексановых структур к алифатическим цепям, обусловливая их гидрогенолитическое расщепление, а взаимодействие водорода с селеном проходит труднее.

Структуру алифатических цепей в керогене характеризует еще одна интересная особенность смол полукоксования кукерсита - концентрационный минимум соединений, принадлежащих к разным гомологическим рядам, но содержащих 12 атомов углерода.

Среди гомологических 5-алкилрезорцинов концентрация 5-гексилрезорцина $\left(\mathrm{C}_{12}\right)$ всегда ниже концентраций его соседних гомологов 5 -пентил- $\left(\mathrm{C}_{11}\right)$ и 5-гептилрезорцинов $\left(\mathrm{C}_{13}\right)$. В работе ['] выдвинуто предположение, что биологическими предшественниками 5-алкилрезорцинов являются полиненасыщенные жирные кислоты, из которых производные резорцина образуются в результате фоссилизации и термического превращения.

В большинстве проб цевой смолы, концентрация кетона $\mathrm{C}_{12}$ ниже концентраций его соседных гомологов. Предполагаем, что указанные структуры образуются при окислении мононенасыщенных жирных кислот.

В ряду нормальных парафинов отчетливый концентрационный минимум $н$-додекана наблюдается реже.

По нащему мнению, этот минимум обусловлен составом жирных кислот планктона $\left(\mathrm{C}_{14}, \mathrm{C}_{16}\right.$ и $\left.\mathrm{C}_{18}\right)$. Их остатками в керогене являются радикалы $\mathrm{C}_{13}, \mathrm{C}_{15}$ и $\mathrm{C}_{17}$, а также большое количество более коротких цепей, которые образовались разными путями из ненасыщенных кислот. Соединения $\mathrm{C}_{12}$ занимают промежуточное положение между указанными двумя группами и, видимо, этим объясняется их малочисленность.

Описанные особенности состава сланцевой смолы показывают, что несмотря на значительный геологический возраст кукерсита, в структуре его керогена хорошо сохранились фрагменты исходного биологического материала. Учитывая малую селективность термической деструкции, можно предполагать, что наблюдаемые закономерности выражены в керогене ярче, чем в продуктах его деструкции. 


\section{Выводы}

1. В смоле полукоксования эстонского горючего сланца-кукерсита из нормальных 1-олефинов повышенную концентрацию имеют $\mathrm{C}_{12}, \mathrm{C}_{14}$ и $\mathrm{C}_{16}$, а из парафинов $-\mathrm{C}_{13}, \mathrm{C}_{15}$ и $\mathrm{C}_{17}$.

2. При термолизе керогена, предварительно дегидрированного селеном, образуется мало олефинов; повышенную концентрацию в смоле имеют $\mu$-парафины $\mathrm{C}_{11}$ и $\mathrm{C}_{13}$.

3. В сланцевой смоле установлен концентрационный минимум соединений, принадлежащих к разным гомологическим рядам, но содержащих 12 атомов углерода. Явление обусловлено составом жирных кислот, при фоссилизации которых образовались исходные структуры этих соединений в керогене.

\section{Л ИТЕРА Т У РА}

1. Клесмент И. Р., Хнмия твердого топлива, № 2, 33 (1973)

2. Е фимов В. М., Лилле Ю., Пийк Э., Тульп М., Мурд А., В сб.: Химия и технология горючих сланцев и продуктов их переработки, вып. 12, Л., 1963, c. 90 .

3. Уров Қ., Клесмент И., Эйзен О., Изв. АН ЭССР, Хим. Геол. (в печати).

4. Касберг А. Ф.. Клесмент И. Р.. Химия твердого топлива, № 1, 107 (1969).

5. W i e 1 A., Erdoel-Erdgas-Zeitschr., 85, Nr. 2, 51 (1969),

6. В ален т а 3., В сб.: Установление структуры органических соединений физическими методами, кн. НI, М., 1967, с. 154.

7. M a t su mo to T., J. Chem. Soc. Japan, Pure Chem. Sect., 72, 68 (1951).
Институт химии
Академии наук Эстонской ССР
Поступила в редакцию 14/XII 1972

\section{KLESMENT, K. UROV, O. EISEN}

\section{MONINGAID SEADUSPARASUSI EESTI POLEVKIVIOLI KOOSTISES}

Olis leiduvatest süsivesinikest on kõrgema kontsentratsiooniga normaalsed 1-olefiinid $\mathrm{C}_{12}, \mathrm{C}_{14}$ ja $\mathrm{C}_{16}$ ning parafiinid $\mathrm{C}_{1 \mathrm{~s}}, \mathrm{C}_{15}$ ja $\mathrm{C}_{17}$. Kerogeeni termilisel lagunemisel seleeni juuresolekul moodustub vähe olefiine, parafiinidest on kõrgema kontsentratsiooniga $\mathrm{C}_{11}$ ja $\mathrm{C}_{13}$. Mitmesugustesse homoloogilistesse ridadesse kuuluvad ühendid, mis sisaldavad 12 süsinikuaatomit, on madalama kontsentratsiooniga kui naaberhomoloogid. Need nähtused on tingitud planktonis esinevate rasvhapete koostisest, sest plankton on kerogeeni bioloogiline lähteaine.

\section{KLESMENT, K. UROV, O. EISEN}

\section{SOME REGULARITIES IN THE COMPOSITION OF SEMICOKING OIL OF ESTONIAN OIL SHALE KUKERSITE}

Normal 1-olefins $C_{12}, C_{14}, C_{16}$ and paraffines $C_{13}, C_{15}, C_{17}$ occur in oil in elevated amounts in comparison with the other homologues. By thermal decomposition of kerogen in the presence of selenium only the minor quantities of olefins are formed, but the creating of paraffines $\mathrm{C}_{11}$ and $\mathrm{C}_{13}$ is enhanced. The compounds that belong to various homologue series but have 12 carbon atoms in molecule, are present in smaller amounts than the neighbouring homologues. The phenomena registered are caused by the composition of fatty acids of plankton - the biological precursor of kerogen. 